\title{
Bias Against Overweight Job Applicants in a Simulated Employment Interview
}

\author{
Regina Pingitore, Bernard L. Dugoni, R. Scott Tindale, and Bonnie Spring
}

\begin{abstract}
This study assessed whether moderately obese individuals, especially women, would be discriminated against in a mock employment interview. Potential confounding factors were controlled by having 320 Ss rate videotapes of a job interview that used the same professional actors appearing as normal weight or made up to appear overweight by the use of theatrical prostheses. Results suggested that bias against hiring overweight job applicants does exist, especially for female applicants. Bias was most pronounced when applicants were rated by Ss who were satisfied with their bodies and for whom perceptions of their bodies were central to self-concept. The decision not to hire an obese applicant was, however, only partially mediated by personality attributions. Implications and limitations of these results are discussed.
\end{abstract}

Research on impression formation consistently shows that stereotypes influence judgments about other people (Fiske \& Taylor, 1991). Most theoretical accounts of stereotyping emphasize the mechanism of category accessibility (e.g., Brewer, 1988; Fiske \& Neuberg, 1990; Hamilton, 1981). A salient characteristic (e.g., race and gender) evokes the stereotypic category and brings with it all of the specific information contained in the category. The additional information then becomes part of the basis for the judgment, regardless of its pertinence to the decision at hand.

Some evidence suggests that stereotypes can influence personnel decisions (Fiske, Bersoff, Borgida, Deaux, \& Heilman, 199 1; Heilman, Martell, \& Simon, 1988). In such cases, salient but job-irrelevant attributes play a role in the decision-making process. Body weight may be such an attribute, but it has received only limited attention. A current cultural assumption is that people can remain lean if they will merely exercise and maintain self-control over dietary intake (Brownell, 1991). Given this presumption, body weight is a legitimate datum from which to infer psychological character. Considerable evidence suggests that, in Westernized cultures, those who are

Regina Pingitore and Bonnie Spring, Department of Psychology, Finch University of Health Sciences/The Chicago Medical School, and Hines Veterans Affairs Medical Center; Bernard L. Dugoni, National Opinion Research Center, University of Chicago; R. Scott Tindale, Department of Psychology, Loyola University of Chicago.

This research was funded in part by the U.S. Department of Labor, Women's Bureau Grant 4 IUSC252C 3 to Regina Pingitore. Preparation of this article was also partially funded by a Veterans Affairs Merit Review Grant to Bonnie Spring. We thank Emil J. Posavac for helpful comments on an earlier version of the article and Barbara Rasner, Joe Kaplan, and Eileen Maniowski for assistance in data collection. We also thank Loyola University Center for Instructional Design and Stage Unlimited for assistance in preparing the videotapes and Gingiss Formal Wear for providing the interview attire.

Correspondence concerning this article should be addressed to Regina Pingitore, Department of Psychology, Finch University of Health Sciences/The Chicago Medical School, 3333 Green Bay Road, North Chicago, Illinois 60064 . overweight are stereotypically perceived as having defects of will power, character, and responsibility (DeJong, 1980; Larkin \& Pines, 1979; Spring, Pingitore, Bruckner, \& Penava, in press). The stereotype that the obese are emotionally impaired, lazy, and selfish might be expected to lead to employment discrimination.

Indeed, there is empirical evidence of employment discrimination against the obese. For example, Larkin and Pines (1979) briefly displayed an overweight or a normal weight job candidate, followed by an identical videotape depicting hands filling out a job application. Viewers who associated the application with the overweight person were less likely to perceive the candidate as having desirable qualities that warranted employment. In a similar study, Benson, Severs, Tatgenhorst, and Loddengaard (1980) mailed identical resumes to health administrators. What varied was whether the accompanying photograph displayed a normal-weight applicant or an obese applicant. Their results indicated that overweight applicants were less likely to be contacted by the administrator and, if contacted, were less likely to be hired. Using videotapes, Klesges et al. (1990) showed two different women, one normal weight and one overweight, in a simulated interview for a clerk-receptionist position. The candidates' faces were masked during the interview to eliminate extraneous cues. The findings were that the judges were less likely to advocate hiring the obese applicant, even though she had the same resume as her lean counterpart.

Although suggestive of bias against obese job applicants, the findings to date are open to other interpretations. In all prior studies, different people have played the roles of the overweight and the normal-weight applicants. Therefore, it remains possible that some non-weight-related attribute of the obese person legitimately triggered the appraisal that the applicant was unsuitable. Although facial attractiveness was masked in one study (Klesges et al., 1990), it is plausible that the obese person was otherwise unattractive or exhibited a slumped posture, depressed voice or demeanor, or gestures that suggested a lesser degree of energy, confidence, or enthusiasm than one would desire in a new employee.

A primary objective of this study was to control for these con- 
founding influences by having the same professional actor sequentially assume the roles of the normal-weight and the overweight applicant, while performing identical job interviews in each role. The transformation from normal weight to obese was done through the use of theatrical prostheses. Because the applicant was actually the same person at different body weights, it was possible to ask whether overweight adults are discriminated against in hiring decisions, when all other factors are held constant.

A substantial body of evidence indicates that equally qualified men and women are evaluated unequally when applying for jobs (Arvey, 1979; Cohen \& Bunker, 1975; Heilman, Martell, \& Simon, 1988). Different performance expectations and appraisals are elicited by gender stereotypes that depict men as strong, dominant, and unemotional and women as affiliative, emotional, and highly concerned about appearance (Martell, 1991). Gender stereotypes may also affect the consequences of departing from expectations in the domain of physical appearance, such that breaching body weight norms results in more negative consequences for women than for men.

Indeed, some evidence supports the suggestion that the obesity stereotype is more pronounced for women than for men. Harris, Harris, and Bochner (1982) found that obese women were assigned attributes significantly more negative than those assigned to obese men. Similarly, Stake and Lauer (1987) found that obese women were viewed more negatively than obese men. Additionally, although being overweight interferes with both men's and women's efforts to establish romantic heterosexual relationships, the impediment is significantly greater for women (Gortmaker, Must, Perrin, Sobal, \& Dietz, 1993). It would not be surprising if obese women also suffered greater employment discrimination than their male counterparts, but to date this question has not been studied systematically. A second objective of this study was, therefore, to test the hypothesis that employment discrimination is greater for overweight women than for overweight men.

Gender and body weight are genuinely relevant to performance in a few jobs but only stereotypically related to performance in others. For example, it is legitimate to deny a man the job of a wet nurse or a heavy person the job of a jockey. More often, however, gender and weight are not job-critical, but only seem job-relevant because decision makers rely on stereotypical beliefs about an applicant's characteristics and how these should match job requirements (Heilman, 1983; Olian, Schwab, \& Haberfeld, 1988). For example, women are less preferred as managers because the attributes considered desirable in a manager (e.g., assertiveness, competitiveness, and drivenness) are considered atypical or unattractive in a woman (Heilman, 1983; Massengill \& DiMarco, 1979; Schein, 1973).

Some evidence suggests a bias against hiring obese applicants for sales positions. It is unclear whether this bias originates in stereotyping or is job-fair because a case could be made that maintaining an attractive appearance, including a lean physique, is a legitimate requirement of jobs that entail sales, entertainment, or customer relations. Rothblum, Miller, and Garbutt (1988) found that obese applicants were less likely than lean applicants to be hired for a position involving extensive sales but equally likely to be hired for a business position requiring less interaction with clients. Also, if hired, overweight salespersons were seen as less effective than normal-weight salespersons, and overweight females, in particular, were seen as less desirable work partners (Jasper \& Klassen, 1990). A third purpose of this study was, therefore, to determine whether even moderately overweight applicants, particularly if female, would suffer more discrimination when applying for highly public positions (sales representative) than for positions with limited public contact (computer systems analyst).

When employers subscribe to traditional stereotypes, it may seem to them that behaviors or attributes not in conformity with these stereotypes derive from a job applicant's or employee's negative personal characteristics (Seigfried \& Pohlman, 1981). Negative dispositional inferences are made about women who apply for "traditionally male" jobs (Heilman, Block, Martell, \& Simon, 1989). Negative attributes-including incompetence, emotionality, and self-indulgence-have also been assigned to the very obese (Louderback, 1970; Silverstein, Perdue, Peterson, \& Kelly, 1986). A fourth aim of the study was, therefore, to examine whether negative personality attributions are also made about overweight applicants and whether this attributional process is influenced by an applicant's gender or the job type. A fifth aim was to determine whether negative dispositional inferences actually mediate or explain why employment discrimination against the obese occurs. Thus, we tested the hypothesis that overweight women experience a disadvantage in employment interviews because they are inferred to have negative personality attributes.

A final question was whether it is possible to characterize the attributes that make some individuals more likely than others to discriminate against overweight applicants. It might be expected that individuals who are themselves overweight would be more tolerant of obesity in others, and therefore, less likely to discriminate against overweight applicants. Alternatively, it may be the case that attitudes toward one's own body are more important than actual body weight in determining reactions to another person's body weight. Two components of body schema can be distinguished: the degree to which an individual is satisfied with his or her body and the degree to which the body is important to the self-concept. Body schemata vary considerably across individuals and influence the evaluation of others (Franzoi \& Herzog, 1986; Franzoi \& Shields, 1984; Secord \& Jourard, 1953; Tucker, 1982; Young \& Reeve, 1980). People with a high degree of concern about their own bodies exhibit heightened sensitivity to weight-related information about themselves and others (Markus, Hammill, \& Sentis, 1987). The literature on self-other evaluation suggests that when an attribute is central to one's self-definition and when one is satisfied with that trait, there is a tendency to be both aware and highly critical when judging that aspect of another person (Lewicki, 1983). This leads to the prediction that those with a high body schema, who are both highly concerned and highly satisfied with their own bodies, will react most negatively to obesity in another person.

To summarize, by means of a methodology that should rule out many potentially confounding factors, we assessed whether overweight individuals, especially women, would be discriminated against in an employment decision. In addition, we examined a possible basis for such discrimination by assessing whether the decision maker's attributions about the applicant 
would mediate a decision not to hire an overweight person. Finally, we attempted to identify both situational (job type) and individual difference (body schema) factors that could delimit when weight-related discrimination might occur.

\section{Method}

\section{Subjects}

The subjects were 320 introductory psychology students $(99 \mathrm{men}$, 221 women) at Loyola University of Chicago, who ranged in age from 18 to 26 years $(M=22 ; S D=1.4)$. Students participated in the research on a voluntary basis and received course credit in return for their participation.

\section{Materials}

Videotapes. Eight videotaped simulated job interviews were prepared in a fashion similar to that used by Dugoni (1987). To eliminate differences in attractiveness, communication style, and vocal intonation that result when different actors portray different applicants, only one male and one female actor were filmed. Each actor was videotaped in each of four conditions determined by the crossing of job type (sales representative vs. systems analyst) and body weight (normal vs. overweight). Both actors were of normal weight according to the criteria of the Department of Health, Education, and Welfare (DHEW). For the overweight condition, a professional makeup artist applied special effects makeup and prostheses so that the actors were made to appear $20 \%$ heavier or about $120 \%$ of ideal body weight and to meet DHEW's criteria for moderate obesity (Abraham, Johnson, \& Najjar, 1979). The normal-weight female actor weighed $142 \mathrm{lb}(64.4 \mathrm{~kg})$ and was $66.5^{\prime \prime}$ $(1.69 \mathrm{~m})$ tall. For the overweight condition, she was made up to appear to weigh approximately $170 \mathrm{lb}$. The normal-weight male weighed 162 $\mathrm{lb}(73.5 \mathrm{~kg})$ and was $68.75^{\prime \prime}(1.73 \mathrm{~m})$ tall. For the overweight condition, he was made up to appear to weigh approximately $194 \mathrm{lb}$. To create a naturalistic appearance, the special effects makeup artist modeled the physiques of 5 men and 5 women who were the same height as the actors and weighed within $5 \mathrm{lb}$ of the intended overweight physiques. To guide the size and placement of the prostheses, the makeup artist matched the clothes sizes, hip and waist measurements, and overall physical appearance of the pilot subjects. Professional actors from the Chicago Theater Guild portrayed the applicants and were specifically instructed to keep their character's vocal intonation, body movements, gestures, and posture the same in all conditions. To further minimize the possibility that wearing the prostheses subtly altered the actors' behavior, the actors were not permitted to view themselves or receive social feedback from others while fitted with the prostheses. To match the tapes as closely as possible, multiple "takes" of each condition were videotaped and then edited to make vocal intonation and pitch, facial expressions, and seating positions the same in all conditions.

Applicant's materials. A job description and applicant's resume were constructed for two positions. The job description for the retail sales representative position requested a highly responsible, productive, professional adult who would be able to portray the company's image. The description for the systems analyst position requested a highly responsible, productive, professional adult who would work independently with only limited public contact. The resumes and dialogue used in the interviews were identical except for the manipulated variables of gender and weight. The information contained in the resumes and interview protocols dealt with job relevant attributes such as previous experience, education, motivation, and so on. The applicants portrayed were neither extremely good nor extremely poor in their presentation and qualifications, because the potential influences of weight and gender might have been minimized for job candidates with extreme character- istics. All applicant materials were pilot tested to ensure that they depicted applicants who possessed average abilities.

\section{Measures}

Rater's demographic features. A demographic questionnaire was used to assess participants' age, gender, height, and body weight. Raters were divided into four weight categories on the basis of body mass index $(\mathrm{BMI})=\left[(\right.$ weight in $\mathrm{kg}) /\left(\right.$ height in $\left.\left.\mathrm{m}^{2}\right)\right]$ : underweight $(<20)$, normal weight $(20-25)$, overweight $(25.1-30)$, and obese $(>30.1)$.

Applicant's perceived personality dispositions. Subjects' attributions about the applicant's personality were assessed by having the subjects rate applicants on a series of 16 paired personal dispositions derived from Larkin and Pines (1979). Adjective pairs-such as productive-nonproductive, decisive-indecisive, attractive-unattractive, and competent-incompetent-were rated with 7-point scales, on which lower values denoted a negative disposition and higher values denoted a positive disposition. An overall index of the applicant's positive personality attributes was constructed by summing the responses to the 16 items (Cronbach's alpha $=.87$ ).

Hiring decision. Subjects indicated whether they would hire the job applicant by using a 7-point scale, where $1=$ definitely not hire and $7=$ definitely hire.

Rater's body schema and weight satisfaction. Two aspects of body self-concept were incorporated into a measure of body schema: satisfaction-dissatisfaction with the body (satisfaction index) and the importance or centrality of body awareness to the self-concept (centrality index). The Body Esteem Scale (BES; Franzoi \& Shields, 1984) was used to quantify the rater's degree of satisfaction with various body parts and processes. To assess the centrality of body awareness to the self-concept, subjects rated the importance of each BES item with a 5-point scale (Richards, Boxer, Petersen, \& Albrecht, 1990). A total body schema score was created for each subject by multiplying (weighting) the body satisfaction rating for each BES item times the rating of that item's importance and then summing the scores. A median split was used to identify individuals who scored above and below the 50th percentile on this measure. Finally, subjects also made a rating that specifically characterized their degree of weight consciousness by using a 7-point rating of satisfaction with body weight.

Applicant's perceived weight. The weight manipulation was assessed after all other measures were completed by having subjects rate the applicant's body weight on a 7-point scale, where $1=$ underweight and 7 = overweight.

\section{Procedure}

Subjects were randomly assigned to view one of the eight videotapes (overweight vs. normal weight $\times$ male vs. female applicant $\times$ systems analyst vs. sales representative job). Subjects read the job description and the applicant's resume before watching one of the eight simulated, videotaped job interviews. After watching the interviews, subjects rated the job applicants and completed the demographic and body schema questionnaires.

\section{Results}

\section{Manipulation Check}

A two-way analysis of variance (ANOVA) with applicant's weight and gender as factors supported the effectiveness of the weight manipulation. When fitted with prosthetic fillers, the applicants were seen as significantly heavier $(M=6.8, S D=.46)$ than when shown as normal weight $(M=3.6, S D=.48), F(1$, $319)=129.74, p<.001$. Neither the main effect of gender nor 
the interaction between weight and gender was significant, which suggests that the male and female actors were, in the appropriate conditions, seen as comparably average and overweight.

\section{Hiring Decision}

To test the major hypotheses, data on the hiring decisions were analyzed by a five-factor ANOVA with the following between-subjects factors: applicant's weight (normal-overweight), applicant's gender (male-female), job description (sales-system analyst), rater's gender (male-female), and rater's body schema (high-low). Results of this analysis are presented in Table 1. The means and standard deviations for the complete design are presented in Table 2.

Are overweight applicants subject to bias in interview evaluations? Whether overweight applicants experience bias in in-

Table 1

Analysis of Variance Summary for the Hiring Decision and Atribution Index

\begin{tabular}{|c|c|c|c|c|}
\hline \multirow[b]{2}{*}{ Source } & \multicolumn{2}{|c|}{$\begin{array}{l}\text { Hiring } \\
\text { recommendation }\end{array}$} & \multicolumn{2}{|c|}{ Attribution index } \\
\hline & $F(1,288)$ & $\omega^{2}$ & $F(1,288)$ & $\omega^{2}$ \\
\hline Weight (W) & 223.228 & .346 & 82.889 & .198 \\
\hline Applicant gender (A) & 68.178 & .104 & 0.259 & - \\
\hline Body schema (B) & 2.443 & - & 0.148 & - \\
\hline Job type $(J)$ & 6.614 & .008 & 2.596 & - \\
\hline Rater's gender $(\mathrm{R})$ & 3.217 & - & 0.452 & - \\
\hline \multicolumn{5}{|l|}{ Two-way } \\
\hline$W \times A$ & 12.081 & .017 & 0.125 & - \\
\hline $\mathrm{W} \times \mathrm{B}$ & 6.539 & .008 & 0.045 & - \\
\hline $\mathbf{W} \times \mathbf{J}$ & 0.005 & - & 0.660 & - \\
\hline $\mathrm{W} \times \mathrm{R}$ & 0.218 & - & 4.222 & .007 \\
\hline $\mathbf{A} \times \mathbf{B}$ & 0.693 & - & 0.498 & - \\
\hline$A \times J$ & 0.211 & - & 1.186 & - \\
\hline$A \times R$ & 0.026 & - & 1.264 & - \\
\hline $\mathrm{J} \times \mathrm{B}$ & 0.122 & - & 0.065 & - \\
\hline $\mathrm{R} \times \mathbf{B}$ & 0.794 & - & 0.929 & - \\
\hline $\mathrm{J} \times \mathrm{R}$ & 0.302 & - & 0.002 & - \\
\hline \multicolumn{5}{|l|}{ Three-way } \\
\hline $\mathrm{W} \times \mathrm{A} \times \mathrm{B}$ & 10.481 & .014 & 1.811 & - \\
\hline $\mathrm{W} \times \mathrm{A} \times \mathrm{J}$ & 0.000 & - & 0.414 & - \\
\hline $\mathbf{W} \times \mathbf{A} \times \mathbf{R}$ & 0.351 & - & 1.559 & - \\
\hline $\mathrm{W} \times \mathrm{B} \times \mathrm{J}$ & 0.294 & - & 0.140 & - \\
\hline $\mathbf{W} \times \mathbf{B} \times \mathbf{R}$ & 5.989 & .007 & 2.139 & - \\
\hline $\mathbf{W} \times \mathbf{J} \times \mathbf{R}$ & 1.091 & - & 0.758 & - \\
\hline $\mathrm{A} \times \mathrm{B} \times \mathbf{J}$ & 0.085 & - & 1.424 & - \\
\hline $\mathrm{A} \times \mathrm{B} \times \mathrm{R}$ & 0.026 & - & 1.978 & - \\
\hline $\mathbf{A} \times \mathbf{J} \times \mathbf{R}$ & 0.058 & - & 0.289 & - \\
\hline $\mathrm{B} \times \mathbf{J} \times \mathbf{R}$ & 0.013 & - & 0.000 & - \\
\hline \multicolumn{5}{|l|}{ Four-way } \\
\hline $\mathbf{W} \times \mathbf{A} \times \mathbf{B} \times \mathbf{J}$ & 2.277 & - & 8.144 & .017 \\
\hline $\mathbf{W} \times \mathbf{A} \times \mathbf{B} \times \mathbf{R}$ & 0.396 & - & 3.982 & .007 \\
\hline $\mathbf{W} \times \mathbf{A} \times \mathbf{J} \times \mathbf{R}$ & 0.747 & - & 0.154 & - \\
\hline $\mathbf{W} \times \mathbf{B} \times \mathbf{J} \times \mathbf{R}$ & 0.335 & - & 1.693 & - \\
\hline $\mathbf{A} \times \mathbf{B} \times \mathbf{J} \times \mathbf{R}$ & 2.705 & - & 1.731 & - \\
\hline \multicolumn{5}{|l|}{ Five-way } \\
\hline $\mathbf{W} \times \mathbf{A} \times \mathbf{B} \times \mathbf{J} \times \mathbf{R}$ & 0.001 & - & 1.212 & - \\
\hline$M S$ & 0.849 & & 132.263 & \\
\hline
\end{tabular}

Nole. $\quad \omega^{2}$ effect sizes are presented only for $F$ ratios significant at $p \leq$ .05 . All other $F$ ratios are nonsignificant. terview evaluations was tested by examining the main effect of applicant's weight on the hiring decision. As shown in Table 1, a main effect of applicant's weight was significant and indicated that overweight applicants ( $M=4.22, S D=1.17$ ) were indeed recommended for employment significantly less often than their equally qualified normal-weight counterparts $(M=5.75$, $S D=.93$ ). The effect size (omega squared) indicated that the applicant's body weight explained $34.6 \%$ of the variance in the hiring decision and was the most powerful predictor studied in this experiment. However, as seen in Table 1, this main effect is embedded in significant higher order interactions that will be discussed below.

Is bias against the overweight greater for women than for men? The main effect of applicant's gender was significant, indicating that female applicants $(M=4.55, S D=1.3)$ were less likely to be hired than their male counterparts $(M=5.40, S D=1.0)$. Gender bias against women explained $10.4 \%$ of the variance in the hiring decision, although this effect is also qualified by higher order interactions.

Analysis of the interaction between applicant's weight and gender tested the prediction that employment bias is greater for overweight women than for overweight men. As indicated in Table 1, this interaction was significant and accounted for about $2 \%$ of the variance in the hiring decision. Simple effects analyses were used to determine whether overweight women experience greater employment discrimination than overweight men. This necessitated the comparison of gender at each level of applicant's weight. The likelihood of hiring a normal-weight woman $(M=5.52, S D=.98)$ did not differ from the likelihood of hiring a normal weight $\operatorname{man}(M=5.9, S D=.82)$, with gender accounting for a nonsignificant portion of variance in the hiring decision. However, within the overweight category, overweight men $(M=4.83, S D=.96)$ were significantly more likely to be hired than overweight women $(M=3.61, S D=1.0), F(1,288)=$ $138.04, p<.01$, with applicant's gender accounting for $27 \%$ of the variance in the hiring decision. To determine whether weight has a more pronounced effect for women than it does for men, we examined the percentage of variance in the hiring decision accounted for by applicant's weight. For female applicants, weight accounted for $47 \%$ of the variance in the hiring decision, $F(1,155)=144.5, p<.01$. For men, although weight continued to account for a significant portion of the variance in the hiring decision, its effect was less pronounced, $R^{2}=.29 ; F(1$, $166)=67.8, p<.01$. Using Fisher's $z_{\mathrm{r}}$ transformation (Ferguson, 1976), we compared the correlations corresponding to these percentages of variance and found them to be significantly different $(Z=2.23, p<.05$ ), indicating that weight had a more pronounced effect for female than for male applicants.

Taken together, these findings support the hypothesis that employment discrimination is, in general, greater for overweight women than for overweight men. It is important to note, however, that these effects are also embedded in a three-way interaction with rater's body schema, the results of which will be discussed below.

Who is most apt not to hire an overweight adult? To determine whether it is possible to characterize the attributes that make some individuals more likely to discriminate against overweight applicants, we first examined the interaction between the rater's body schema and the applicant's weight. Table 1 shows 
Table 2

Means, Standard Deviations, and Cell Sizes for the Hiring Recommendation as a Function of Applicant Weight and Gender, Rater Gender and Body Schema, and Job Type

\begin{tabular}{|c|c|c|c|c|}
\hline \multirow[b]{3}{*}{ Variable } & \multicolumn{4}{|c|}{ Applicant } \\
\hline & \multicolumn{2}{|c|}{ Normal weight } & \multicolumn{2}{|c|}{ Overweight } \\
\hline & Male & Female & Male & Female \\
\hline \multicolumn{5}{|c|}{ Female raters } \\
\hline \multicolumn{5}{|l|}{$\begin{array}{c}\text { Low schema } \\
\text { Sales job }\end{array}$} \\
\hline$M$ & 5.80 & 5.41 & 4.83 & 4.00 \\
\hline$S D$ & 0.84 & 1.06 & 0.92 & 1.22 \\
\hline$n$ & 5 & 17 & 18 & 9 \\
\hline \multicolumn{5}{|c|}{ Analyst job } \\
\hline$M$ & 6.06 & 5.27 & 5.16 & 4.37 \\
\hline$S D$ & 0.68 & 0.96 & 1.17 & 1.12 \\
\hline$n$ & 16 & 15 & 19 & 19 \\
\hline \multicolumn{5}{|l|}{ High schema } \\
\hline \multicolumn{5}{|l|}{ Sales job } \\
\hline$M$ & 6.17 & 5.46 & 4.64 & 3.00 \\
\hline$S D$ & 0.39 & 1.13 & 0.81 & 0.73 \\
\hline$n$ & 12 & 13 & 11 & 16 \\
\hline \multicolumn{5}{|c|}{ Analyst job } \\
\hline$M$ & 6.00 & 6.15 & 4.91 & 3.27 \\
\hline$S D$ & 0.73 & 0.55 & 0.83 & 0.65 \\
\hline$n$ & 16 & 13 & 11 & 11 \\
\hline \multicolumn{5}{|c|}{ Male raters } \\
\hline \multirow{2}{*}{\multicolumn{5}{|c|}{$\begin{array}{c}\text { Low schema } \\
\text { Sales job }\end{array}$}} \\
\hline & & & & \\
\hline$M$ & 6.00 & 5.00 & 4.50 & 3.29 \\
\hline$S D$ & 0.82 & 1.00 & 1.29 & 1.38 \\
\hline$n$ & 4 & 3 & 4 & 7 \\
\hline \multicolumn{5}{|c|}{ Analyst job } \\
\hline$M$ & 6.60 & 5.50 & 4.00 & 4.00 \\
\hline$S D$ & 0.55 & 1.38 & 0.63 & 0.71 \\
\hline$n$ & 5 & 6 & 6 & 5 \\
\hline \multicolumn{5}{|l|}{ High schema } \\
\hline \multicolumn{5}{|l|}{ Sales job } \\
\hline$M$ & 5.58 & 5.43 & 4.71 & 3.29 \\
\hline$S D$ & 1.17 & 0.79 & 0.76 & 0.76 \\
\hline$n$ & 19 & 7 & 7 & 7 \\
\hline \multicolumn{5}{|l|}{ Analyst job } \\
\hline$M$ & 6.20 & 5.67 & 5.20 & 3.33 \\
\hline$S D$ & 0.45 & 0.58 & 0.84 & 0.52 \\
\hline$n$ & 5 & 3 & 5 & 6 \\
\hline
\end{tabular}

that this two-way interaction was significant, which indicates that raters with a high body schema exhibited greater selection bias in favor of normal-weight applicants. As stated above, however, applicant's weight and gender interacted with rater's body schema. Although the effect was small (.014) and not predicted a priori, we probed this three-way interaction in an attempt to explore further how individual differences might delimit employment bias against overweight applicants. Simple effects analyses were used to assess whether the effects of applicant's weight and gender varied by differences in rater's body schema. Results revealed that raters with a low body schema endorsed hiring normal-weight applicants in preference to overweight applicants, $F(1,288)=74.57, p<.01$, and although they tended to endorse hiring an overweight male applicant $(M=4.9, S D=$
$1.06)$ in preference to an overweight female applicant $(M=4.0$, $S D=1.17$ ), this effect was not significant. In contrast, the analysis of raters with a high body schema showed that applicant's weight interacted significantly with applicant's gender, $F(1,288)$ $=24.09, p<.01$. As shown in Table 1, high-schema individuals were significantly more likely to hire an overweight male applicant than an overweight female applicant, $F(1,288)=144.8, p$ $<.01$. Also indicated in Table 1 is a significant three-way interaction of applicant's weight and rater's body schema with rater's gender. A probe of this interaction showed that overweight applicants were less preferred than normal-weight applicants, particularly when evaluated by women with high body schema. Because the two components of the body schema index (body satisfaction and body importance) were significantly but not highly correlated, $r=.34, p<.05$, we also assessed whether each body-schema component yielded similar results. A median split was performed on each component, and both were analyzed separately in the full factorial ANOVA. The results of two analyses essentially yielded the same results as the overall analysis of body schema. These findings suggest that individuals differ in the degree to which their hiring decisions are influenced by an applicant's gender and body weight. Findings regarding body schema should, however, be interpreted cautiously because they reflect a small effect size, could have resulted spuriously from the large number of tests performed, and might not be generalizable beyond this particular sample.

The construct of body schema includes surplus elements not specifically germane to body weight. Consequently, it remained possible that bias against the obese could be explained more parsimoniously by knowing the rater's weight satisfaction or actual body weight. When the rater's assessment of weight satisfaction was examined in the full factorial ANOVA, however, weight satisfaction had no significant effect on the hiring decision either by itself or in combination with any other factor. Similarly, the rater's actual weight also failed to affect the hiring decision. Because including the rater's weight in the full factorial ANOVA model resulted in empty cells, the data for this analysis were collapsed across rater's gender and job description. No factorial effect of rater's BMI was found in the collapsed analysis, and there was no significant factorial effects change when rater's BMI was covaried out of the full five-factor ANOVA. It seems, then, that the body appraisal processes that result in bias against the obese may be more complex than what is captured by the simpler variable of weight consciousness, although it must be acknowledged that the body schema construct was measured with greater psychometric power than was weight satisfaction.

Is employment bias against overweight people heightened in jobs with extensive public contact? As shown in Table 1, a main effect for job type was significant, which indicates that raters were more likely to recommend applicants applying for the systems analyst position $(M=5.14, S D=1.25)$ than those applying for the sales position $(M=4.83, S D=1.34)$. If, however, employment bias is heightened when physical appearance can be construed as salient to job requirements, then the ANOVA should indicate a significant interaction between applicant's weight and job type, possibly moderated by applicant's gender. On the contrary, however, no interaction involving job type was significant. This suggests that the relevance of appear- 
Table 3

Means and Standard Deviations of Dispositional Attributions as a Function of Applicant Weight and Gender, Rater Gender and Body Schema, and Job Type

\begin{tabular}{|c|c|c|c|c|}
\hline \multirow[b]{3}{*}{ Variable } & \multicolumn{4}{|c|}{ Applicant } \\
\hline & \multicolumn{2}{|c|}{ Normal weight } & \multicolumn{2}{|c|}{ Overweight } \\
\hline & Male & Female & Male & Female \\
\hline \multicolumn{5}{|c|}{ Female raters } \\
\hline \multicolumn{5}{|l|}{ Low schema } \\
\hline$M$ & 78.80 & 88.58 & 78.50 & 71.89 \\
\hline$S D$ & 8.52 & 10.39 & 12.22 & 16.35 \\
\hline \multicolumn{5}{|c|}{ Analyst job } \\
\hline$M$ & 89.94 & 90.27 & 73.42 & 79.74 \\
\hline$S D$ & 10.51 & 11.89 & 13.86 & 13.86 \\
\hline \multicolumn{5}{|l|}{ High schema } \\
\hline \multicolumn{5}{|l|}{ Sales job } \\
\hline$M$ & 90.75 & 88.23 & 70.64 & 73.63 \\
\hline$S D$ & 9.75 & 10.55 & 13.90 & 8.22 \\
\hline \multicolumn{5}{|c|}{ Analyst job } \\
\hline$M$ & 86.13 & 94.23 & 78.27 & 75.09 \\
\hline$S D$ & 11.47 & 7.98 & 13.93 & 14.87 \\
\hline \multicolumn{5}{|c|}{ Male raters } \\
\hline Low schema & & & & \\
\hline & & & & \\
\hline$M$ & 89.00 & 80.00 & 73.25 & 74.71 \\
\hline$S D$ & 11.01 & 9.00 & 13.30 & 9.92 \\
\hline \multicolumn{5}{|l|}{ Analyst job } \\
\hline$M$ & 89.20 & 83.83 & 66.33 & 84.20 \\
\hline$S D$ & 8.04 & 5.38 & 10.07 & 13.95 \\
\hline \multicolumn{5}{|l|}{ High schema } \\
\hline \multicolumn{5}{|l|}{ Sales job } \\
\hline$M$ & 83.63 & 82.29 & 84.00 & 77.71 \\
\hline$S D$ & 10.63 & 8.47 & 9.91 & 7.84 \\
\hline \multicolumn{5}{|c|}{ Analyst job } \\
\hline$M$ & 92.40 & 84.67 & 85.40 & 72.83 \\
\hline$S D$ & 8.90 & 4.50 & 9.71 & 16.35 \\
\hline
\end{tabular}

ance to job requirements had no effect on the decision to hire or not hire an overweight applicant.

Are more negative personality dispositions attributed to overweight applicants? To determine whether raters made more negative personality attributions about overweight applicants, especially women, the full five-factor ANOVA was recomputed with the index of perceived positive personality traits as the dependent variable. The results of this analysis are presented in Table 1; cell means and standard deviations appear in Table 3.

As shown in Table 1, the main effect of applicant's weight was significant, revealing that overweight applicants $(M=87.79, S D$ $=10.21$ ) were indeed perceived more negatively than normalweight applicants $(M=76.04, S D=12.96)$. In addition, there was a significant interaction between applicant's weight and rater's gender. Although both male and female raters attributed fewer positive personality traits to obese applicants (male's mean rating $=77.25, S D=12.26$; female's mean rating $=$ $75.54, S D=13.26$ ) than normal-weight applicants (male's mean rating $=85.11, S D=8.9$; female's mean rating $=89.08$, $S D=10.58$ ), female raters made a more pronounced differen- tiation on the basis of weight. In fact, the difference between the ratings that female raters assigned to obese versus normalweight applicants was nearly twice as great as the difference for male raters, and this difference was significant in a post hoc analysis, $F(1,288)=9.12, p<.01$. This finding suggests that weight is a more salient judgment criterion for women than men, consistent with women's greater societal pressure to maintain a slim physique.

As Table 1 demonstrates, the effect of applicant's weight was also embedded in two significant four-way interactions involving the applicant's gender, the rater's gender, his or her body schema, and the job type. In both cases, however, the interaction was seemingly caused by an outlying cell formed by six lowschema male raters who made unusually negative attributions about the obese male applicant. Because of the small sample size in this cell, and because each of these interactions accounted for a very small percentage of the total variance $(.01$ and .007$)$, they were not interpreted further.

Do negative personality attributions mediate the relationship between obesity and hiring judgments? Our hypotheses concerning the effects of obesity on hiring judgments were based on the premise that the negative stereotype associated with obesity would lead to negative dispositional attributions about overweight applicants. We expected that the decision not to hire an obese person would be predicted on and mediated by the negative dispositions attributed to that person. To assess this hypothesis, we computed a hierarchical regression analysis that regressed hiring judgments onto the dispositional index and subjects' obesity judgments. We entered the dispositional index first, followed by the rating of the applicant's perceived weight, to discern whether perceived obesity would account for variance unaccounted for by the dispositional index. The results are presented in Table 4 and indicate that personality attributions did account for a significant proportion of variance in the hiring decision. Nonetheless, even after the variance explained by the disposition index was removed, significant residual variance was explained by the applicant's perceived obesity. Because gender and body schema influenced the hiring decision and the attributional ratings, we also ran the regression analyses within each of the four cells defined by these factors. Although the percentage of variance explained by perceived obesity versus dispositional attributions varied across the four cells, perceptions of obesity always accounted for a significant percentage of variance above that explained by personality attributions. Thus,

Table 4

Results of a Hierarchical Regression Analysis Predicting the Hiring Decision From Rater's Attributions and Applicant's Body Weight

\begin{tabular}{lcccc}
\hline \multicolumn{1}{c}{ Variable } & $R^{2}$ & $R^{2}$ change & $F$ & $d f$ \\
\hline Attribution index & .29 & .29 & $135.33^{*}$ & 1,318 \\
Applicant's body weight & .45 & .16 & $83.64^{*}$ & 2,317 \\
\hline
\end{tabular}

Note. The correlations between hiring decision and rater's attributions, applicant's weight and rater's attributions, and applicant's weight and hiring decision were $.55,-.45$, and -.59 , respectively. All correlations were significant at $p<.01$.

$* p<.01$ 
dispositional attributions never completely mediated the relationship between obesity and the hiring judgment. These results indicate that employment bias against overweight applicants can only partially be explained by the negative personality traits attributed to the obese.

\section{Discussion}

Construed from the vantage point of the American preoccupation with maintaining personal control, being overweight may constitute evidence of deficient willpower, character, and responsibility. It would not be surprising, therefore, if overweight people suffered employment discrimination, and indeed, some prior evidence supports this possibility. In all prior studies, however, different people played the roles of the obese and the normal-weight applicants, which left open the possibility that some non-weight-related attribute of the obese person (e.g., unattractiveness, depressed voice or demeanor) may have prompted an appraisal that the applicant was unsuitable. In this study, we controlled for these confounding influences by having the same professional actor perform the roles of the normalweight and the overweight applicant.

Our first question was whether, with all other factors held constant, a selection bias exists against hiring overweight adults. The results provide strong evidence of employment bias against the obese. The applicant's body weight explained about $35 \%$ of the variance in the hiring decision and was the most powerful predictor studied in this experiment. This finding suggests that body weight is indeed a salient attribute in decisions about employment.

The second question was whether overweight women experience greater employment discrimination than overweight men. Surprisingly, this question had not been previously addressed. Once again, support was very strong for the conclusion that overweight women experience greater employment discrimination than overweight men. When considered against a larger background of research findings showing that being a woman generally reduces employment opportunities (Heilman et al., 1988), this finding suggests that being an overweight woman further delimits employability.

The third question was whether bias against hiring obese applicants is more pronounced when physical appearance can be construed as salient to job performance. Contrary to expectations, whether appearance could be construed as relevant to job requirements had no effect on the decision to hire or not hire an overweight person. Overweight applicants were no more likely to be hired for a position requiring minimal public contact than they were for a job requiring extensive public contact. Although it is conceivable that employment bias against the obese operates equivalently regardless of whether appearance is job-relevant or job-irrelevant, as these results suggest, other interpretations are possible. First, because the study subjects were undergraduates who lacked experience in making personnel decisions, they may have overlooked specific job requirements that would have been salient to people more skilled in making hiring decisions. Second, the jobs chosen for comparison may not have been described distinctly enough to highlight the differential job-salience of appearance. Although the job descriptions implied that appearance was more salient for the sales position than the systems analyst position, the differences between the jobs may have been too subtle to be perceived by students who lack professional experience in the workplace. Similarly, the fact that the analysis of the disposition index data (see Table 1) failed to yield an interaction between applicant's weight and job type suggests that subjects perceived the characteristics of the overweight applicants as falling short for both job types. Finally, it may have been that viewing the overweight applicant triggered negative emotions, which strongly biased the evaluative process and the hiring decision and overrode any influence of job type.

Recent research findings suggest that emotions are a powerful determinant of impression formation (Forgas, 1992), and they complement or sometimes even override the influence of cognitions. It is noteworthy that in this study, subjects' cognitive appraisals about applicants' personality dispositions only partially mediated the decision not to hire an obese applicant; much residual variance remained unexplained. Fiske and colleagues (Fiske \& Neuberg, 1990; Fiske \& Pavelchak, 1986) have argued that categories (and thus stereotypes) are structured in such a way that the emotion associated with a particular category is more directly accessed by the category label than are any specific pieces of information (e.g., traits or dispositions) contained in the category. Once a category (e.g., obese) has been triggered by a particular person, the emotion associated with the category remains associated with the person even when other contradictory information is presented (Fiske, 1982; Kulik, 1989). Although the resumes and interview dialogues in this study portrayed the applicants as average, they did provide considerable positive information about the job candidates (good scholastic record and high motivation, etc.). Such positive information may have discouraged the attribution of specific stereotypical traits associated with obesity (e.g., lazy, incompetent), although some such attributions were nonetheless made. According to Fiske's model of category structure, however, the more positive information presented in the resumes and interviews would have done little to dispel the negative emotions evoked by the obese category. The significant variance in the hiring decision explained by subjects' obesity judgments, over and above the variance accounted for by dispositional inferences, may be mediated by affective appraisals of the obese. Emotional and cognitive evaluations may both influence the hiring decision, and the former are less likely to be educable by the provision of information. These findings provide little encouragement for the prospect that employment bias against the obese can be dispelled through training. Although training may discourage employers from making stereotypical attributions about personality traits, it may be much more difficult to prevent basic, affective, gut responses from influencing employment decisions.

Finally, this study aimed to characterize individual differences associated with hiring bias against the obese. Simple weight-related characteristics failed to identify those who were most likely to be biased against hiring overweight adults. This study provided no evidence to suggest that lean raters are differentially disposed to discriminate against obese applicants, although a limitation that must be acknowledged is that weights were self-reported and not objectively verified. Overall body schema was a predictor, however, suggesting that attitudes toward one's body may be a cognitively salient basis for social comparison and judgment. Shrauger and Patterson (1973) ar- 
gued that, when evaluating others, an individual focuses on dimensions, such as the body, that are relevant, prized aspects of the self-image. Because comparing the self to others on the basis of valued competencies permits successful self-aggrandizement, self-esteem is enhanced, and the comparison process is reinforced.

The findings provide greater insight into the social consequences of obesity by suggesting that overweight adults, particularly women, are likely to suffer employment bias. The limitations of the study should be acknowledged, however. First, caution must be exercised before inferring that these results can be generalized to hiring bias in a naturalistic, nonsimulated employment interview. The study's external validity is limited by the fact that its raters were not individuals who are experienced and empowered to make hiring decisions, although it can be noted that no differences have been found between students' and managers' predictions of applicants' job success (Singer \& Bruhns, 1991). A second limitation is that, although we attempted to control for extraneous non-weight-related differences between the job applicants by having the same actor enact both weight conditions, it remains possible that wearing the prostheses generated other subtle behavioral changes, not detected by us, that nonetheless influenced the applicants' apparent suitability for employment. Third, because job qualifications and other attributes (e.g., age) were held constant, it is not possible to evaluate the relative impact of obesity versus other attributes that are typically considered in making employment decisions. However, the fact that even the moderate level of obesity simulated in this study explained $34 \%$ of the variance in the hiring decision demonstrates that weight exerts a potent influence. Whether the strong bias against hiring an overweight job candidate has any justification or consequences for job performance and whether the bias can be overcome if the applicant presents unusually strong credentials are important questions that warrant systematic future study.

\section{References}

Abraham, S., Johnson, C., \& Najjar, M. (1979). Weight by height and age for adults 18-74 years. National Center for Health Statistics. Department of Health, Education and Welfare Pub No. (PHS)79-1656. Hyattsville, MD.

Arvey, R. (1979). Unfair discrimination in the employment interview: Legal and psychological aspects. Psychological Bulletin, 86, 736-765.

Benson, P. L., Severs, D., Tatgenhorst, J., \& Loddengaard, N. (1980). The social costs of obesity: a non-reactive field trial. Social Behavior and Personality, 21, 75-87.

Brewer, M. B. (1988). A dual process model of impression formation. In T. K. Srull \& R. S. Wyer (Eds.), Advances in social cognition (Vol. 1, pp. 1-36). Hillsdale, NJ: Erlbaum.

Brownell, K. (1991). Personal responsibility and control over our bodies: When expectation exceeds reality. Health Psychology, 10, 303310.

Cohen, S. L., \& Bunker, K. A. (1975). Subtle effects of sex-role stereotypes on recruiter hiring decisions. Journal of Applied Psychology, 60. $566-572$.

DeJong, W. (1980). The stigma of obesity: The consequences of naive assumptions concerning the causes of physical deviance. Journal of Health and Social Behavior, 21, 75-87.

Dugoni, B. (1987). The importance of job outcomes and perceptions of bias in selection interviews. In A. Larocque (Ed.), Psychologie du tra- vail et nouveaux milieux de travail [The psychology of work and new work environments]. Sillery, Québec, Canada: Presses de l'Université du Québec.

Ferguson, C. A. (1976). Statistical analysis in psychology and education. New York: McGraw-Hill.

Fiske, S. T. (1982). Schema-triggered affect: Applications to social perception. In M. S. Clark \& S. T. Fiske (Eds.), Affect and cognition: The 17th annual Carnegie Symposium on Cognition (pp. 55-78). Hillsdale, NJ: Erlbaum.

Fiske, S. T., Bersoff, D. N., Borgida, E., Deaux, K., \& Heilman, M. E. (1991). Social science research on trial: Use of sex stereotyping research in Price Waterhouse v. Hopkins. American Psychologist, 46, 1049-1060.

Fiske, S. T., \& Neuberg, S. L. (1990). A continuum of impression formation, from category-based to individuating processes: Influences of information and motivation on attention and interpretation. In M. P. Zanna (Ed.), Advances in experimental social psychology (Vol. 23, pp. 1-74). San Diego, CA: Academic Press.

Fiske, S. T., \& Pavelchak, M. A. (1986). Category-based versus piecemeal-based affective responses: Developments in schema-triggered affect. In R. M. Sorrentino \& E. T. Higgins (Eds.), Handbook of motivation and cognition: Foundations of social behavior (pp. 167-203). New York: Guilford Press.

Fiske, S. T., \& Taylor, S. E. (1991). Social cognition (2nd ed.). New York: McGraw-Hill.

Forgas, J. (1992). On mood and peculiar people: Affect and person typicality in impression formation. Journal of Personality and Social Psychology, 62, 863-875.

Franzoi, S., \& Herzog, M. (1986). The Body Esteem Scale: A convergent and discriminant validity study. Journal of Personality Assessment, 50, 24-31.

Franzoi, S., \& Shields, S. (1984). The Body Esteem Scale: Multidimensional structure and sex differences in a college population. Journal of Personality Assessment, 48, 173-178.

Gortmaker, S., Must, A., Perrin, J., Sobal, A., \& Dietz, W. (1993). Social and economic consequences of overweight in adolescence and young adulthood. New England Journal of Medicine, 329, 1008-1012.

Hamilton, D. L. (1981). Stereotyping and intergroup behavior: Some thoughts on the cognitive approach. In D. L. Hamilton (Ed.), Cognitive processes in stereotyping and intergroup behavior (pp. 333-353). Hillsdale, NJ: Erlbaum.

Harris, M., Harris, R., \& Bochner, S. (1982). Fat, four-eyed and female: Stereotypes of obesity, glasses and gender. Journal of Applied Social Psychology, 12, 503-516.

Heilman, M. (1983). Sex bias in work settings: The lack of fit model. Research in Organizational Behavior, 5, 269-298.

Heilman, M., Block, C., Martell, R., \& Simon, R. (1989). Has anything changed? Current characterizations of men, women and managers. Journal of Applied Psychology, 74, 935-942.

Heilman, M., Martell, R., \& Simon, M. (1988). The vagaries of sex bias: Conditions regulating the underevaluation, equivaluation, and overevaluation of female job applicants. Organizational Behavioral and Human Decision Processes, 41, 98-110.

Jasper, C., \& Klassen, M. (1990). Perceptions of salepersons' appearance and evaluation of job performance. Perceptual and Motor Skills, $71,563-566$.

Klesges, R., Klem, M., Hanson, C., Eck, L., Ernst, J., O'Laughlin, D., Garrot, A., \& Rife, R. (1990). The effect of applicant's health status and qualifications on simulated hiring decisions. International Journal of Obesity, 14, 527-535.

Kulik, C. T. (1989). The effects of job categorization on judgments of the motivating potential score. Administrative Sciences Quarterly, 34 , 68-90. 
Larkin, J., \& Pines, H. (1979). No fat persons need apply. Sociology of Work and Occupations, 6, 312-327.

Lewicki, P. (1983). Self-image bias in person perception. Journal of Personality and Social Psychology, 45, 384-393.

Louderback, L. (1970). Fat power: Whatever you weigh is right. New York: Hawthorn Books.

Markus, H., Hammill, R., \& Sentis, K. (1987). Thinking fat: Self-schemas for body weight and the processing of relevant information. Journal of Applied Social Psychology, 17, 50-71.

Martell, R. (1991). Sex bias at work: The effects of attentional and memory demands on performance ratings of men and women. Journal of Applied Social Psychology, 21, 1939-1960.

Massengill, D., \& DiMarco, N. (1979). Sex roles stereotypes and requisite management characteristics: A current replication. Sex Roles, 5 , $561-570$

Olian, J., Schwab, D., \& Haberfeld, Y. (1988). The impact of applicant gender compared to qualifications on hiring recommendations: A meta-analysis of experimental studies. Organizational Behavioral and Human Decision Processes, 41, 180-195.

Richards, M. H., Boxer, A. M., Petersen, A. C., \& Albrecht, R. (1990). Relation of weight to body image in pubertal girls and boys from two communities. Developmental Psychology, 26, 313-321.

Rothblum, E., Miller, C., \& Garbutt, B. (1988). Stereotypes of obese female job applicants. International Journal of Eating Disorders, 7, 277-283.

Schein, V. (1973). The relationship between sex role stereotypes and requisite management characteristics. Journal of Applied Psychology, $57,95-100$.
Secord, P., \& Jourard, S. (1953). The appraisal of body-cathexis: Body cathexis and the self. Journal of Consulting Psychology, 5, 343-347.

Seigfried, W., \& Pohlman, C. (1981). Order and task effects on the evaluation of male and female applicants. Academic Psychology Bulletin, 1, 89-96.

Shrauger, J., \& Patterson, M. (1973). Self-evaluation and the selection of dimensions for evaluating others. Journal of Personality, 42, 569585.

Silverstein, B., Perdue, L., Peterson, K., \& Kelly, E. (1986). The role of the mass media in promoting a thin standard of bodily attractiveness for women. Sex Roles, 14, 19-533.

Singer, M., \& Bruhns, C. (1991). Relative effect of applicant work experience and academic qualification on selection interview decisions: $A$ study of between-sample generalizability. Journal of Applied Psychology, 76, 550-559.

Spring, B., Pingitore, R., Bruckner, E., \& Penava, S. (in press). Obesity: Idealized or stigmatized? Sociocultural influences on the meaning and prevalence of obesity. In A. Hills and M. L. Wahlqvist (Eds.), Fitness and fatness. London: Smith-Gordon.

Stake, J., \& Lauer, M. (1987). The consequences of being overweight: A controlled study of gender differences. Sex Roles, 17, 31-47.

Tucker, L. (1982). Relationship between perceived somatotype and body cathexis of college males. Psychological Reports, 10, 983-989.

Young, M., \& Reeve, T. (1980). Discriminant analysis of personality and body image factors of females differing in percent body fat. Perceptual and Motor Skills, 50, 547-552.

Received April 26, 1993

Revision received April 5, 1994

Accepted April 11, 1994

\title{
P\&C Board Appoints Editor for New Journal: Journal of Experimental Psychology: Applied
}

In 1995, APA will begin publishing a new journal, the Journal of Experimental Psychology: Applied. Raymond S. Nickerson, PhD, has been appointed as editor. Starting immediately, manuscripts should be submitted to

\author{
Raymond S. Nickerson, PhD \\ Editor, JEP: Applied \\ Department of Psychology \\ Tufts University \\ Medford, MA 02155
}

The Journal of Experimental Psychology: Applied will publish original empirical investigations in experimental psychology that bridge practically oriented problems and psychological theory. The journal also will publish research aimed at developing and testing of models of cognitive processing or behavior in applied situations, including laboratory and field settings. Review articles will be considered for publication if they contribute significantly to important topics within applied experimental psychology.

Areas of interest include applications of perception, attention, decision making, reasoning, information processing, learning, and performance. Settings may be industrial (such as human-computer interface design), academic (such as intelligent computer-aided instruction), or consumer oriented (such as applications of text comprehension theory to the development or evaluation of product instructions). 